\title{
Ascorbic Acid Controls Lethal Browning and Pluronic F-68 Promotes High-frequency Multiple Shoot Regeneration from Cotyldonary Node Explant of Okra (Abelmoschus esculentus L.)
}

\author{
Muhammad Irshad, Hafiz Muhammad Rizwan, Biswojit Debnath, \\ Muhammad Anwar, Min Li, Shuang Liu, Bizhu He, and Dongliang Qiu ${ }^{1}$ \\ College of Horticulture, Fujian Agriculture and Forestry University, Fuzhou, \\ Fujian 350002, China
}

Additional index words. Abelmoschus esculentus, in vitro browning, regeneration enhancers, tissue culture

\begin{abstract}
The regeneration frequency of okra (Abelmoschus esculentus) is greatly influenced by its genetic makeup and recalcitrant nature. Phenolic secretion, in particular, is a major problem in okra tissue culture. This study describes a reproducible, rapid, and more efficient in vitro regeneration method using cotyledonary node explants of okra. Explants were incubated on Murashige and Skoog (MS) medium containing different concentrations and combinations of various plant growth regulators (PGRs) [benzyladenine (BA), thidiazuron (TDZ), and $\alpha$-naphthylacetic acid (NAA)], and regeneration enhancers [silver nitrate $\left(\mathrm{AgNO}_{3}\right)$ and Pluronic $\mathrm{F}-68$ ]. Cut ends of cotyledonary node segments rapidly turned brown and cultures failed to establish. Antibrowning additives, such as activated charcoal (AC), ascorbic acid (AA), and $\mathrm{AgNO}_{3}$ at various concentrations in PGR-free MS basal medium were tested for their ability to control phenolic secretion from explants. Among these additives, $15 \mathrm{mg} \cdot \mathrm{L}^{-1}$ AA was found to be optimal for controlling phenolic secretion, resulting in healthy explants and culture establishment. The highest number of shoots (a mean of $9.3 \pm 0.9$ shoots per cotyledonary node explant) was obtained on MS media containing $0.5 \mathrm{mg} \cdot \mathrm{L}^{-1} \mathrm{NAA}+1$ $\mathrm{mg} \cdot \mathrm{L}^{-1} \mathrm{TDZ}+\mathbf{0 . 1} \%$ Pluronic F-68. Individual shoots were elongated on MS medium +1 $\mathrm{mg} \cdot \mathrm{L}^{-1} \mathrm{BA}+0.1 \mathrm{mg} \cdot \mathrm{L}^{-1}$ gibberellic acid $\left(\mathrm{GA}_{3}\right)$ (shoot length $\left.5.3 \pm 0.2 \mathrm{~cm}\right)$ and rooted on $1 / 2 \mathrm{MS}$ medium $+1 \mathrm{mg} \cdot \mathrm{L}^{-1}$ indole-3-butyric acid (IBA) and $200 \mathrm{mg} \cdot \mathrm{L}^{-1} \mathrm{AC}(5.3 \pm 0.2$ roots per shoot). Rooted plantlets were acclimatized in plastic pots inside a plant growth chamber at $25 \pm 2{ }^{\circ} \mathrm{C}$ and $70 \%$ relative humidity, with an $80 \%$ survival rate. This optimized protocol can be used for producing transgenic plants of commercial okra cultivars through genetic transformation.
\end{abstract}

Okra (A. esculentus), commonly known as lady's fingers, is an economically important vegetable crop cultivated worldwide, with India leading in production followed by Nigeria and Iraq (FAO, 2013). It is an excellent source of dietary fiber, and the

Received for publication 19 July 2017. Accepted for publication 21 Sept. 2017.

The financial assistance from the FAFU scholarship program, provided by the Fujian Agriculture and Forestry University of China, is gratefully acknowledged.

M.I. designed and carried out all the experiments, and prepared the manuscript. H.M.R. helped in performing the experiments. B.D. helped in statistical analysis. M.A. revised the manuscript. M.L. provided the materials and reagents. S.L. revised the manuscript. B.Z.H. arranged for technical help. D.L.Q. conceived the work, and revised and finalized the manuscript.

${ }^{1}$ Corresponding author. E-mail: qiud11970@fafu. edu.cn. protein content in its pod has been reported to be $4.41 \%$ to $4.55 \%$ (Düzyaman and Vural, 2001). Okra consumption prevents a number of diseases and conditions such as hepatitis, ulcers, diabetes, and cancer (Kumar et al., 2009; Sabitha et al., 2011; Sunilson et al., 2008). However, okra plants are highly susceptible to various biotic and abiotic factors, which adversely affect the growth and yield of the crop and result in great economic losses (Hamon and Van Sloten, 1995). Okra has two major limitations, namely, its unique genome with a large number of chromosomes $2 n=130$ (Nwangburuka et al., 2011) and precocious chromosome movement during metaphase in wide hybridization (Fatokun, 1987), that hamper its genetic improvement through conventional breeding.

These limitations could be addressed by genetic engineering methods to complement conventional breeding techniques. However, okra is one of the most recalcitrant crops for genetic modification with the lack of an efficient tissue culture system among the chief reasons. There have been several published reports on okra regeneration because it was first successfully accomplished by Mangat and Roy (1986) using nodes and shoot tips of in vitro grown seedlings (Anisuzzaman et al., 2010; Kabir et al., 2008). Direct organogenesis is a good alternative regeneration method to attain multiple shoot production. This method has less somaclonal variation, is less time consuming (Yildirim and Turker, 2014), and has a greater success rate than indirect regeneration methods (Gerszberg et al., 2015). In addition, it has the capability to overcome the limitation of genotype dependence in plant tissue culture systems (Hedayat et al., 2009). Thus far, with respect to okra, shoot regeneration has been attained from various tissues including shoot tips, cotyledonary nodes, and embryos (Anisuzzaman et al., 2010; Mangat and Roy, 1986; Narendran et al., 2013). However, constraints such as exudation of phenolic compounds and oxidation during the excision of explants, accumulation of brown compounds in culture medium, necrosis of explants, and slow in vitro response have made successful okra tissue culture an elusive process. To our knowledge, no previous study has monitored and addressed these problems during the in vitro regeneration of okra. Phenolic compounds are secreted from wounded regions of explants as a defense response (Lorenzo et al., 2001), and oxidation of these compounds results in browning of culture media and plant tissues (Jones and Saxena, 2013). Oxidative enzymes such as phenylalanine ammonia lyase, polyphenol oxidase (PPO), and peroxidase are considered as markers of oxidative metabolism (Andersone and Ievinsh, 2002). These enzymes catalyze the aerobic oxidation of phenolic compounds to quinines that are auto-oxidized to brown pigments that ultimately inhibit plant cellular growth (Jain et al., 2014; Tabiyeh et al., 2005). In addition, accumulation of ethylene in the culture medium as a result of low gas exchange is another cause of browning of explants during in vitro culture (Gerszberg et al., 2015).

To date, three main classes of additives have been used to alleviate browning of cultured explants. These include adsorbents such as polyvinylpyrrolidone and AC, which adsorb phenolic compounds secreted into the media by inoculated explants (Thomas, 2008); reducing agents such as citric acid (CA) and AA, which reduce the phenolic compound accumulation in the media (Klenotičová et al., 2013); and phenolic inhibitors such as $\mathrm{AgNO}_{3}$, which act directly on the explant tissue to inhibit phenolic secretion in the target site (Kumar et al., 2016).

Ascorbic acid is a strong antioxidant; it scavenges oxygen radicals produced during explant injury, decreasing the oxidative browning (Titov et al., 2006). In addition, this compound has an essential role during plant morphogenesis (Horemans et al., 2000) and is involved in cell division, cell differentiation, and cell elongation of apical meristems 
of Aloe barbadensis Mill (Kaviani, 2014) and cotyledonary nodes of Vicia faba (Abdelwahd et al., 2008). AA has been shown to inhibit the browning of cultured tissues and improve morphogenesis in Cavendish banana (Ko et al., 2009) and Brachylaena huillensis (Ndakidemi et al., 2014). Similarly, $\mathrm{AgNO}_{3}$ is a potent ethylene inhibitor and its presence in culture medium has been reported to inhibit browning and induce in vitro shoot production in many plant species (Haque et al., 2015; Kabir et al., 2013; Mookkan and Andy, 2014). Several hypotheses have been postulated on possible mechanisms of $\mathrm{AgNO}_{3}$ in reducing explant browning and promoting plant regeneration. Kumar et al. (2009) postulated that silver ions are potent inhibitors of ethylene activity as they compete for the binding sites on membrane-localized ethylene receptors. In another report, $\mathrm{AgNO}_{3}$ has been reported to function as an inhibitor of ethylene activity through the $\mathrm{Ag}^{2+}$ ions by reducing the receptor capacity to bind ethylene (Bais et al., 2000). In addition to its role as an antibrowning agent, several reports indicate that it is effective in regulating morphogenesis and induces multiple shoot production (Fernandez et al., 1999; Kumar et al., 2016).

Media composition is an important determinant of regeneration efficiency. N6benzylaminopurine (BAP) is the cytokinin that has been commonly used in in vitro shoot proliferation of okra (Anisuzzaman et al., 2010; Narendran et al., 2013). However, recently, TDZ (a phenylurea-type cytokinin) has been commonly used to promote shoot proliferation and regeneration in various plant species (Faisal et al., 2014) and can replace the use of BAP. In addition, supplementation of regeneration enhancers such as Pluronic F-68 and $\mathrm{AgNO}_{3}$ in PGRs added culture medium plays an important role to promote multiple shoot production (Lowe et al., 1994; Yildirim and Turker, 2014). However, to our knowledge, there are no published reports on multiple shoot production from cotyledonary nodes of okra using different concentrations and combinations of PGRs and regeneration enhancers. Therefore, in the current study, we established an efficient in vitro protocol for inducing multiple shoots from cotyledonary node explants of $A$. esculentus. We examined the influence of $\mathrm{AC}, \mathrm{AA}$, and $\mathrm{AgNO}_{3}$ on controlling phenolic secretions from cotyledonary node explants. In addition, we examined the influences of PGRs and regeneration enhancers (Pluronic F-68 and $\mathrm{AgNO}_{3}$ ) on shoot proliferation. In a previous study, an efficient protocol was developed for in vitro regeneration of okra mainly through callus with reduced phenolic secretion using antibrowning additives such as AC, CA, and AA (Irshad et al., 2017). The present study provides the first report on in vitro shoot induction from okra cotyledonary nodes using antibrowning additives and regeneration enhancers in culture medium, which may constitute a favorable alternative for making transgenic plants of commercial genotypes of okra.

\section{Materials and Methods}

Preparation of $\mathrm{AA}, \mathrm{AgNO}_{3}$, and Pluronic F-68 stock solutions. Analytical grade AA, $\mathrm{AgNO}_{3}$, and Pluronic F-68 were purchased from Solarbio ${ }^{\circledR}$. Stock solutions of AA and $\mathrm{AgNO}_{3}\left(0.50 \mathrm{mg} \cdot \mathrm{L}^{-1}\right)$ and Pluronic F-68 (5\%, $\mathrm{w} / \mathrm{v})$ were prepared in sterile distilled water, and then dispensed into screw-capped bottles $\left(\mathrm{Cosmo}^{\circledR}\right.$, Beijing, China), and were stored at $4{ }^{\circ} \mathrm{C}$ until use.

Surface sterilization and seed germination. Seeds of A. esculentus 'Wufu' were obtained from the germplasm bank of the Institute of Vegetable Science, Fujian Agriculture and Forestry University, Fuzhou, Fujian, China. Surface sterilization of okra seeds was completed following the method of Irshad et al. (2017). The sterilized seeds were cultured in baby food jars $(5 \times 9 \mathrm{~cm})\left(\mathrm{Cosmo}^{\circledR}\right)$ containing half strength MS basal medium without PGR. For all experiments, $8 \mathrm{~g} \cdot \mathrm{L}^{-1}$ agar and $25 \mathrm{~g} \cdot \mathrm{L}^{-1}$ sucrose were supplemented in the MS medium, and the $\mathrm{pH}$ was adjusted to 5.8 with $0.5 \mathrm{~N} \mathrm{NaOH}$ or $\mathrm{HCl}$ before autoclaving at $121{ }^{\circ} \mathrm{C}$ for $20 \mathrm{~min}$. The cultured seeds were placed in dark conditions in a growth room at $25 \pm 2{ }^{\circ} \mathrm{C}$ for $2 \mathrm{~d}$ and then incubated under 16-h photoperiod with fluorescent light (cool-white Philips, Beijing, China: $\left.60 \mu \mathrm{mol} \cdot \mathrm{m}^{-2} \cdot \mathrm{s}^{-1}\right)$. Agar, Sucrose, $\mathrm{NaoH}$ and $\mathrm{HCl}$ were purchased from Macklin Co. Ltd. (Shanghai, China).

Fortification of antibrowning additives in culture medium. We evaluated the influence of three different antibrowning additives, $\mathrm{AC}, \mathrm{AA}$, and $\mathrm{AgNO}_{3}$ on phenolic secretion from explants to culture medium. These compounds, with concentrations ranging from 1 to $300 \mathrm{mg} \cdot \mathrm{L}^{-1}$, were added to growth regulator-free MS medium. For the AA treatment, the $\mathrm{pH}$ of the AA solution was adjusted to 5.8 in $50 \mathrm{~mL}$ MS medium and then the solution was added to autoclaved media through filter sterilization using $0.22 \mu \mathrm{m}$ syringe filter (Stardent, Guangdong, China), whereas $\mathrm{AC}$ and $\mathrm{AgNO}_{3}$ were added to the medium before autoclaving. Explants were incubated for an initial 2 weeks in an antibrowning added medium, and then were transferred to the multiple shoot induction medium.

Culturing of explants on antibrowning additives supplemented medium. Cotyledonary node explants $(0.5 \mathrm{~cm})$ were aseptically excised from 10-d-old in vitro grown seedlings and were placed in sterile baby food jars containing growth regulator-free MS medium with antibrowning additives for 2 weeks of initial culture. Data on phenolic secretion and culture vigor (healthy and reproducible cultures) were recorded after 2 weeks.

Multiple shoots induction and proliferation. Healthy cultures ( 2 weeks-old) with no browning symptoms were transferred to sterile baby food jars containing MS basal salt with different combinations and concentrations of PGRs; $\alpha$-NAA $\left(0.1,0.2,0.5\right.$, and $\left.1 \mathrm{mg} \cdot \mathrm{L}^{-1}\right)$ in combination with BA $(0.1,0.5,1,1.5$, and 2 $\left.\mathrm{mg} \cdot \mathrm{L}^{-1}\right)$ or TDZ $\left(0.1,0.5,1,1.5\right.$, and $\left.2 \mathrm{mg} \cdot \mathrm{L}^{-1}\right)$.
PGRs and growth enhancer combinations were also prepared; NAA $\left(0.2\right.$ and $\left.0.5 \mathrm{mg} \cdot \mathrm{L}^{-1}\right)$ were used in combination with BA $(0.5$ and $\left.1 \mathrm{mg} \cdot \mathrm{L}^{-1}\right)$ or TDZ $\left(0.5\right.$ and $\left.1 \mathrm{mg} \cdot \mathrm{L}^{-1}\right)$ either in association with $\mathrm{AgNO}_{3}\left(2\right.$ and $\left.3 \mathrm{mg} \cdot \mathrm{L}^{-1}\right)$ or with Pluronic F-68 (0.1\% and 0.3\%). Cultures were maintained in a growth room under a $16-\mathrm{h}$ photoperiod $\left(80 \mu \mathrm{mol} \cdot \mathrm{m}^{-2} \cdot \mathrm{s}^{-1}\right)$ at $25 \pm 2{ }^{\circ} \mathrm{C}$. Subculturing was performed after 2 weeks. Shoots initiation and growth characteristics were observed every week, whereas, data for mean number of shoots per explant and multiple shoot formation frequency were recorded after 4 weeks of culture.

Shoot elongation. Well-developed shoots $(1-1.5 \mathrm{~cm})$ were isolated from the mass of proliferated shoots and were cultured on MS medium supplemented with different concentrations of BA $\left(0.1,0.5\right.$, and $\left.1 \mathrm{mg} \cdot \mathrm{L}^{-1}\right)$ and $\mathrm{GA}_{3}\left(0.1,0.5\right.$, and $\left.1 \mathrm{mg} \cdot \mathrm{L}^{-1}\right)$ separately or in combination. The medium also contained $200 \mathrm{mg} \cdot \mathrm{L}^{-1}$ AC. Cultures were incubated in a growth room at $25 \pm 2{ }^{\circ} \mathrm{C}$ under a 16-h photoperiod of $80 \mu \mathrm{mol} \cdot \mathrm{m}^{-2} \cdot \mathrm{s}^{-1}$ light intensity. Data for mean shoot length and shoot elongation frequency were recorded after 3 weeks of culture.

In vitro rooting and acclimatization of plantlets. Elongated shoots $(2.0-5.0 \mathrm{~cm}$ in length) were transferred to a rooting medium consisting half strength of MS salts, $200 \mathrm{mg} \cdot \mathrm{L}^{-1} \mathrm{AC}$, and varying concentrations $\left(0.5,1,1.5,2\right.$, and $\left.2.5 \mathrm{mg} \cdot \mathrm{L}^{-1}\right)$ of either indole3 -acetic acid (IAA) or IBA. The number of roots per shoot, root formation frequency, and mean length of induced roots were recorded after 4 weeks of incubation.

Hardening and field transfer. The rooted plants were carefully separated from the root inducing medium, washed with distilled water, and transferred to sterilized (autoclaved at $121{ }^{\circ} \mathrm{C}$ for $40 \mathrm{~min}$ ) plastic pots containing vermiculite and sand (3:1). Thereafter, these cultures were maintained in a growth chamber for 2 weeks at $25 \pm 2{ }^{\circ} \mathrm{C}, 70 \% / 60 \%$ humidity, and 16-h light/8-h dark photoperiods. The plants were then transferred to a greenhouse under natural conditions and watered once every $2 \mathrm{~d}$ for further growth and development.

Statistical analysis. The experiments were arranged in a completely randomized design $(n=10)$, and each experiment was repeated three times. MS medium without PGRs was used as a control treatment. Oneway analysis of variance was performed using SPSS version 17 (SPSS Inc., Chicago, IL) for all statistical analyses, and differences between treatment means were determined using Duncan's multiple range test $(P<0.05)$. Phenolic secretion frequency was calculated according to the following formula (Kumar et al., 2015).

\section{$\%$ of phenolic secretion \\ $=\frac{\text { number of explants showing phenolic secretion }}{\text { total number of explants }} \times 100$}

Furthermore, the percentage of culture vigor was determined using a formula similar to the previously given formula, through visual 
determination of healthy and browning free explants.

\section{Results}

Culture establishment. Cotyledonary nodes excised from 10-d-old in vitro grown seedlings were found as suitable sources of explants for culture establishment. Initially, cut ends of cotyledonary nodes, and then whole explants, turned dark brown in color and secreted phenolic compounds into the culture media, which adversely affected culture establishment. This phenomenon caused the death of explants, and none of those that survived produced viable shoots (Fig. 1A-D). To overcome this challenge, cotyledonary node explants were incubated on MS basal medium (PGR free) supplemented with antibrowning additives, $\mathrm{AC}, \mathrm{AA}$, and $\mathrm{AgNO}_{3}$.

Effects of antibrowning additives on phenolic secretion and culture vigor. Activated charcoal, $\mathrm{AA}$, and $\mathrm{AgNO}_{3}$ treatments all showed a significant decrease in phenolic secretion and improvement in explant vigor (Figs. 1 and 2), with AA being the most efficient antibrowning additive. Only $15 \%$ of the cultures in the control treatment survived, but showed stunted growth (Fig. 1A-D). Comparing the antibrowning additives, cultures started on AA treatment, of various concentrations, were of good quality with $20 \%$ to $51 \%$ vigor, with best results observed in $15 \mathrm{mg} \cdot \mathrm{L}^{-1}$ AA (51\% vigor with only $2.8 \%$ phenolic secretion) and reached maturity with $100 \%$ survival rate (data not shown).
$\mathrm{AgNO}_{3}\left(1,2,4\right.$, and $\left.5 \mathrm{mg} \cdot \mathrm{L}^{-1}\right)$ treatments had $29 \%, 23 \%, 20 \%$, and $15 \%$ vigor, respectively. Overall, the lowest vigor values, ranging from $9 \%$ to $21 \%$, were recorded for the AC supplemented medium. Noticeably, among treated additives, the lowest phenolic secretions ranging from $0 \%$ to $18 \%$ were observed for the AC supplemented medium, whereas the highest phenolic secretions, between $14 \%$ and $69 \%$, were recorded for the $\mathrm{AgNO}_{3}$ supplemented medium.

Effects of $P G R$ s and regeneration enhancers on shoot initiation and multiplication. Multiple shoots were induced when cultures were inoculated in MS media supplemented with different concentrations of PGRs alone or in combination with regeneration enhancers. In general, the formation of multiple shoots on cotyledonary node cultures was observed after 2 weeks of cultivation. In the absence of PGRs, multiple shoot production was not observed and only single shoots developed (Tables 1 and 2). Mediums supplemented with TDZ in association with NAA induced higher shoot production with higher frequencies as compared with those observed with cultures maintained on media supplemented with BA and NAA (Table 1). The number of shoots ( 3.7 per explant), with $46 \%$ response, obtained on MS basal medium supplemented with $0.5 \mathrm{mg} \cdot \mathrm{L}^{-1} \mathrm{NAA}$ and $1 \mathrm{mg} \cdot \mathrm{L}^{-1} \mathrm{TDZ}$ was higher than that $(2.3$ per explant), with $32 \%$ response, achieved on $0.5 \mathrm{mg} \cdot \mathrm{L}^{-1} \mathrm{NAA}$ and $1 \mathrm{mg} \cdot \mathrm{L}^{-1} \mathrm{BA}$. The regeneration frequency and shoot number were increased with the addition of regeneration enhancers. Generally, TDZ in combination with NAA and Pluronic F-68 were the most efficient in terms of shoot regeneration number and frequency from cotyledonary raised cultures (Table 2). Best shoot proliferation was achieved with $1 \mathrm{mg} \cdot \mathrm{L}^{-1} \mathrm{TDZ}$ in combination with $0.2 \mathrm{mg} \cdot \mathrm{L}^{-1} \mathrm{NAA}$ and $0.1 \%$ Pluronic F-68 (9.3 shoots; $75 \%$ response) (Table 2; Fig. 3D and E). Supplementation of $0.1 \%$ Pluronic F-68 into 1 $\mathrm{mg} \cdot \mathrm{L}^{-1} \mathrm{TDZ}$ and $0.5 \mathrm{mg} \cdot \mathrm{L}^{-1} \mathrm{NAA}$ increased shoot number by $\approx 3$-fold (from 3.7 to 9.3 ). Percentage of explants regenerated shoots was also increased from $45 \%$ to $75 \%$ (Tables 1 and 2). Noticeably, a lower concentration of Pluronic F-68 was beneficial for shoot proliferation compared with higher concentration of Pluronic F-68 and all tested concentrations of $\mathrm{AgNO}_{3}$ with BA and NAA (Table 2). In this study, TDZ and NAA combinations induced shoot proliferation better than BA and NAA combinations, whereas among the regeneration enhancers, Pluronic F-68 in combination with TDZ and NAA resulted in the best shoot proliferation compared with $\mathrm{AgNO}_{3}$.

Effects of PGRs and regeneration enhancers on phenotypes of regenerated shoots. Regenerated shoots morphologically varied with PGRs and growth enhancer treatments. Multiple shoots regenerated with NAA and BA combination were dark green in color and lengthy in size. By contrast, shoots induced with NAA and TDZ were light green and exhibited reduced shoot length. Shoots developed on $\mathrm{AgNO}_{3}$

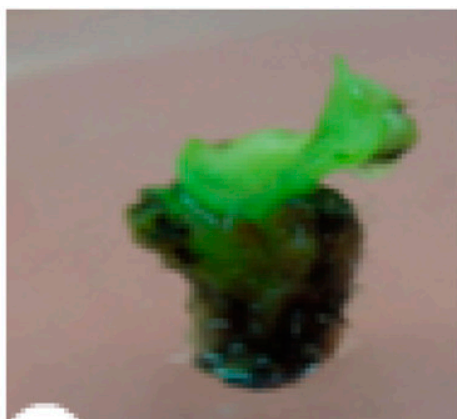

A
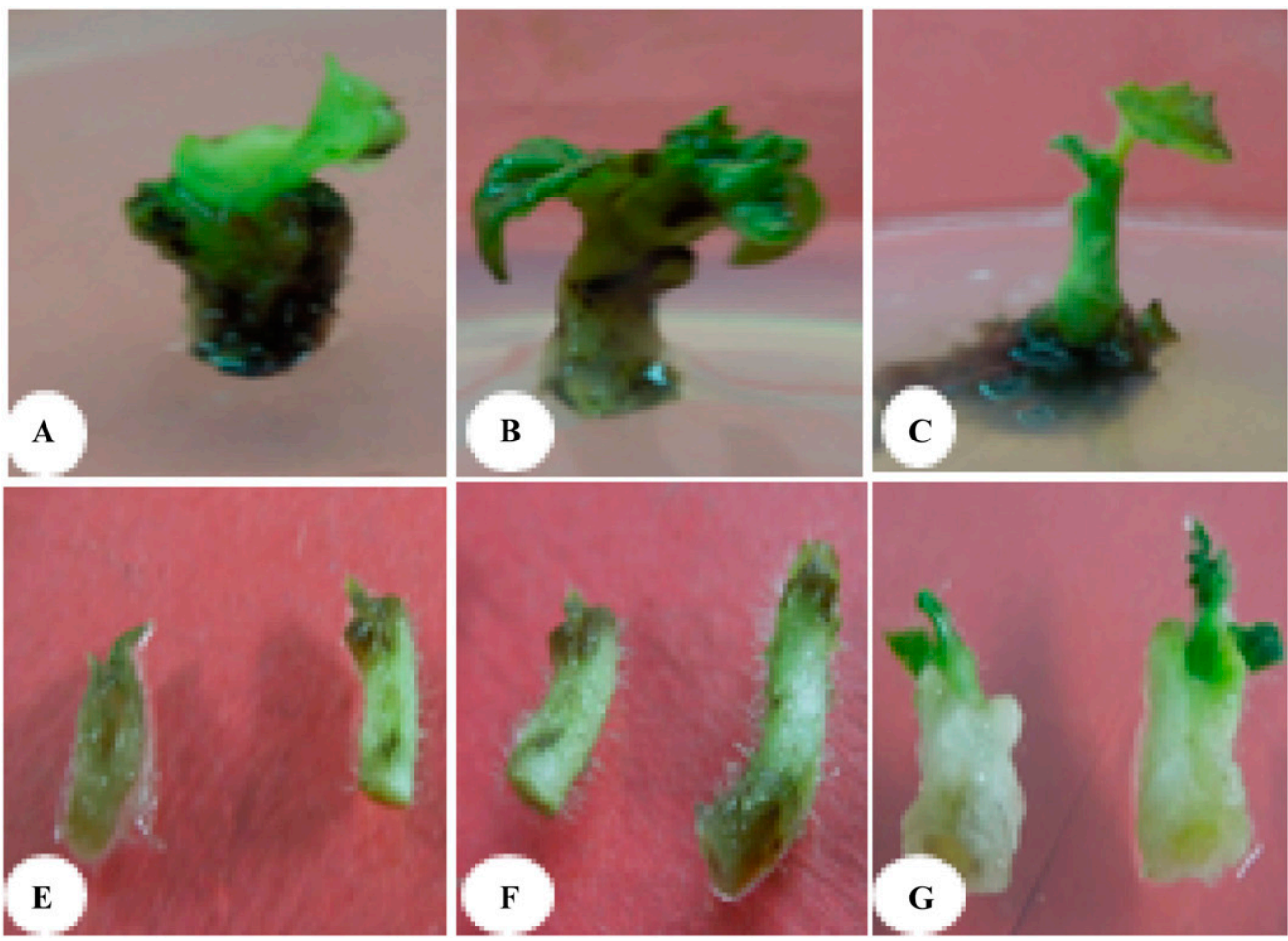
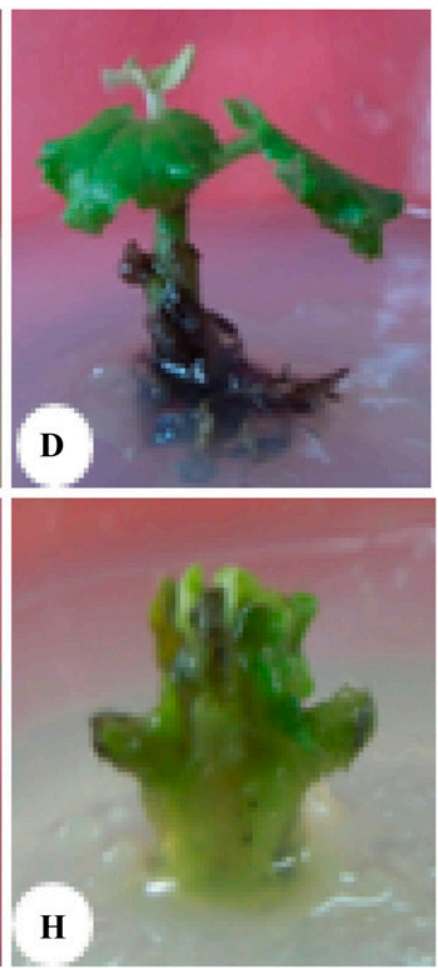

Fig. 1. Effect of antibrowning additives on controlling phenolic secretion from explants in okra tissue culture. Excessive phenolic secretion and abnormal growth of explants cultured on medium without antibrowning agents (A-D), explants cultured on activated charcoal-supplemented medium (E), explants cultured on $\mathrm{AgNO}_{3}-$ supplemented medium $(\mathbf{F})$, and explants cultured on ascorbic acid-supplemented medium $(\mathbf{G}$ and $\mathbf{H})$. For $(\mathbf{E}-\mathbf{H})$ data were collected after 2 weeks of culture. 


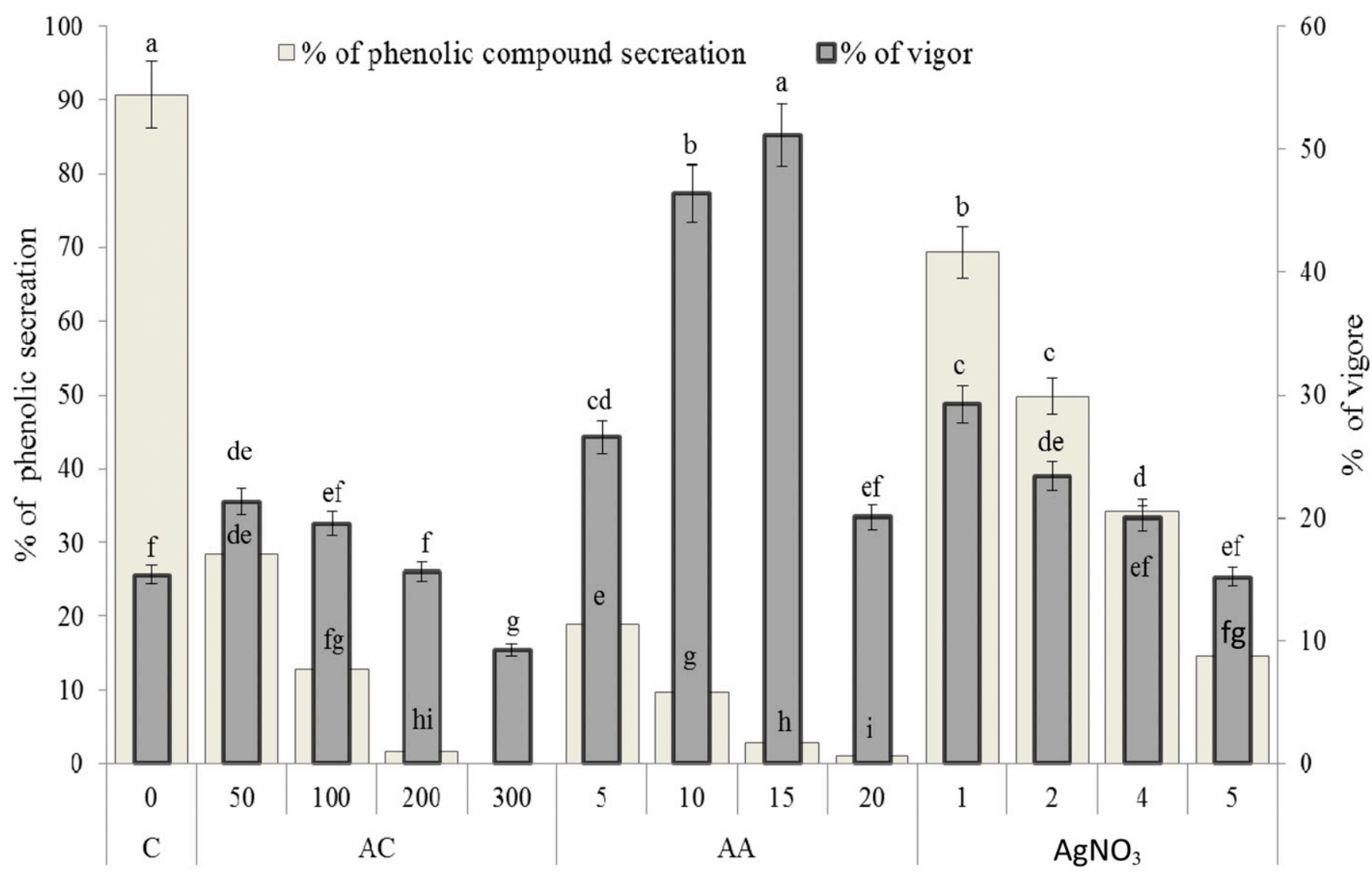

Anti- browning addatives $\mathrm{mg} \mathrm{l}^{-1}$

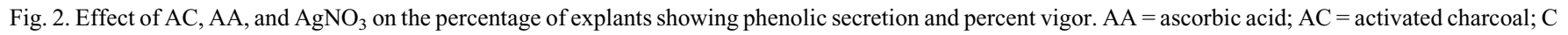
$=$ control; $\mathrm{AgNO}_{3}=$ silver nitrate.

Table 1. Effect of different concentrations and combinations of plant growth regulators (PGRs) on shoot regeneration from cotyledonary node explants of Abelmoschus esculentus.

\begin{tabular}{|c|c|c|c|c|}
\hline \multicolumn{3}{|c|}{ PGR $\left(\mathrm{mg} \cdot \mathrm{L}^{-1}\right)$} & \multirow[b]{2}{*}{ No. of shoots per explant } & \multirow[b]{2}{*}{ Shoot proliferation $(\%$} \\
\hline NAA & $\mathrm{BA}$ & TDZ & & \\
\hline$\overline{0}$ & 0 & - & $1.0 \pm 0.0 \mathrm{~b}$ & 5 \\
\hline 0.1 & 0.1 & - & $1.3 \pm 0.3 \mathrm{ab}$ & 13 \\
\hline 0.2 & 0.5 & - & $1.7 \pm 0.3 \mathrm{ab}$ & 38 \\
\hline 0.5 & 0.5 & - & $2.0 \pm 0.6 \mathrm{ab}$ & 41 \\
\hline 0.5 & 1 & - & $2.3 \pm 0.7 \mathrm{ab}$ & 32 \\
\hline 1 & 1.5 & - & $1.3 \pm 0.3 \mathrm{ab}$ & 45 \\
\hline 1 & 2 & - & $1.3 \pm 0.3 \mathrm{ab}$ & 27 \\
\hline 0.1 & - & 0.1 & $1.7 \pm 0.3 \mathrm{ab}$ & 11 \\
\hline 0.2 & - & 0.5 & $2.7 \pm 0.3 \mathrm{ab}$ & 32 \\
\hline 0.5 & - & 0.5 & $2.3 \pm 0.3 \mathrm{ab}$ & 57 \\
\hline 0.5 & - & 1 & $3.7 \pm 0.9$ a & 46 \\
\hline 1 & - & 1.5 & $2.0 \pm 0.6 \mathrm{ab}$ & 31 \\
\hline 1 & - & 2 & $2.0 \pm 0.6 \mathrm{ab}$ & 26 \\
\hline
\end{tabular}

Values represent mean $\pm \mathrm{sE}$; data were recorded after 4 weeks of culture. Values with same letter within a column are not significantly different $(P<0.05)$ based on Duncan's multiple range test. Best result is shown in bold. $\mathrm{BA}=$ benzyladenine; $\mathrm{NAA}=$ naphthylacetic acid; $\mathrm{TDZ}=$ thidiazuron .

supplemented medium were compact and showed stunted growth, the leaves were abnormal with reduced leaf area and extensive withering (Fig. 3F), and this phenomenon increased with increasing amounts of $\mathrm{AgNO}_{3}$ for both tested combinations of PGRs. This showed the negative effect of $\mathrm{AgNO}_{3}$ on the morphogenetic response of okra. On the other hand, multiple shoots induced on Pluronic F-68 added medium were healthy, specifically when a lower concentration was used in combination with NAA and TDZ. Both shoots and leaves appeared an intense green and healthy, showing increased chlorophyll content in the shoots (Fig. 3D and E). Moreover, multiple shoots proliferated vigorously with subculturing in new media, and appeared as bunches with several shoots of optimum length.

Shoot elongation. Well-proliferated shoots were excised individually from shoot bunches and cultured on MS medium containing different concentrations of $\mathrm{BA}$ and $\mathrm{GA}_{3}$ singly or in combination. The medium also contained $200 \mathrm{mg} \cdot \mathrm{L}^{-1} \mathrm{AC}$. We assessed the shoot elongation by measuring the average shoot length after 3 weeks of culture (Table 3). We obtained the largest shoot length $(5.3 \mathrm{~cm})$ and highest percentage of shoot elongation (64\%) in the MS medium supplemented with $1 \mathrm{mg} \cdot \mathrm{L}^{-1} \mathrm{BA}$ and 0.1 $\mathrm{mg} \cdot \mathrm{L}^{-1} \mathrm{GA}_{3}$ (Fig. 3G). Supplementation of MS medium with $1 \mathrm{mg} \cdot \mathrm{L}^{-1} \mathrm{BA}$ alone also induced increased shoot elongation $(51 \%)$. In contrast, supplementation of MS medium with $\mathrm{GA}_{3}$ alone, for all tested concentrations, was not effective at inducing shoot elongation.

In vitro rooting and acclimatization. Elongated shoots (3-4 cm length) were rooted readily in half strength MS medium supplemented with different concentrations of IBA and IAA along with $200 \mathrm{mg} \cdot \mathrm{L}^{-1} \mathrm{AC}$. Eighty-two percent of cloned shoots were rooted in vitro on $1 / 2 \mathrm{MS}$ salts with $1 \mathrm{mg} \cdot \mathrm{L}^{-1}$ IBA and $200 \mathrm{mg} \cdot \mathrm{L}^{-1} \mathrm{AC}$ (Fig. $\left.3 \mathrm{H}\right)$. The roots (5.3 roots of $4.5-\mathrm{cm}$ length) produced on this medium were strong and healthy compared with those (4.0 roots of $3.7 \mathrm{~cm}$ length) produced on the medium containing a higher concentration $\left(1.5 \mathrm{mg} \cdot \mathrm{L}^{-1}\right)$ of IAA (Table 4$)$. On lower (less than $1 \mathrm{mg} \cdot \mathrm{L}^{-1}$ ) concentrations of IBA, shoots exhibited delayed and poor response, whereas on higher $\left(2.0 \mathrm{mg} \cdot \mathrm{L}^{-1}\right)$ 
Table 2. Effect of different concentrations of plant growth regulators (PGRs) in combination with silver nitrate $\left(\mathrm{AgNO}_{3}\right)$ and Pluronic F-68 on shoot regeneration from cotyledonary node explants of Abelmoschus esculentus.

\begin{tabular}{|c|c|c|c|c|c|c|}
\hline \multicolumn{3}{|c|}{ PGRs (mg. $\left.\mathrm{L}^{-1}\right)$} & \multirow[b]{2}{*}{$\mathrm{AgNO}_{3}$} & \multirow[b]{2}{*}{ Pluronic (\%) } & \multirow[b]{2}{*}{ No. of shoots per explant } & \multirow[b]{2}{*}{ Shoot proliferation $(\%)$} \\
\hline$\overline{\mathrm{NAA}}$ & $\mathrm{BA}$ & $\overline{\mathrm{TDZ}}$ & & & & \\
\hline$\overline{0}$ & 0 & 0 & 0 & 0 & $1.0 \pm 0.0 \mathrm{~d}$ & 12 \\
\hline 0.2 & 0.5 & - & 2 & - & $3.0 \pm 0.6 \mathrm{bcd}$ & 35 \\
\hline 0.5 & 1 & - & 2 & - & $3.7 \pm 0.9 \mathrm{bcd}$ & 43 \\
\hline 0.2 & 0.5 & - & 3 & - & $4.7 \pm 0.7 \mathrm{bc}$ & 50 \\
\hline 0.5 & 1 & - & 3 & - & $3.0 \pm 0.6 \mathrm{bcd}$ & 49 \\
\hline 0.2 & 0.5 & - & - & 0.1 & $2.7 \pm 0.3 \mathrm{~cd}$ & 55 \\
\hline 0.5 & 1 & - & - & 0.1 & $3.3 \pm 0.9 \mathrm{bcd}$ & 53 \\
\hline 0.2 & 0.5 & - & - & 0.3 & $5.3 \pm 0.3 \mathrm{bc}$ & 53 \\
\hline 0.5 & 1 & - & - & 0.3 & $4.0 \pm 0.6 \mathrm{bcd}$ & 36 \\
\hline 0.2 & - & 0.5 & 2 & - & $3.3 \pm 0.3 \mathrm{bcd}$ & 36 \\
\hline 0.5 & - & 1 & 2 & - & $4.0 \pm 1.0 \mathrm{bcd}$ & 49 \\
\hline 0.2 & - & 0.5 & 3 & - & $4.3 \pm 0.3 \mathrm{bc}$ & 27 \\
\hline 0.5 & - & 1 & 3 & - & $3.7 \pm 0.3 \mathrm{bcd}$ & 28 \\
\hline 0.2 & - & 0.5 & - & 0.1 & $4.0 \pm 0.6 \mathrm{bcd}$ & 62 \\
\hline 0.5 & - & 1 & - & 0.1 & $9.3 \pm 0.9$ a & 75 \\
\hline 0.2 & - & 0.5 & - & 0.3 & $6.0 \pm 0.6 \mathrm{~b}$ & 60 \\
\hline 0.5 & - & 1 & - & 0.3 & $4.7 \pm 0.7 \mathrm{bc}$ & 44 \\
\hline
\end{tabular}

Values represent mean $\pm \mathrm{SE}$; data were recorded after 4 weeks of culture. Values with same letter within a column are not significantly different $(P<0.05)$ based on Duncan's multiple range test. Best result is shown in bold. $\mathrm{BA}=$ benzyladenine; NAA = naphthylacetic acid; TDZ = thidiazuron .

concentration of IBA, the number (2.7) and length $(2.8 \mathrm{~cm})$ of roots were reduced. Plantlets with a well-developed root system, with three to four leaves were transferred to plastic pots containing vermiculate and garden soil $(1: 1 \mathrm{v} / \mathrm{v})$, and then were incubated in a growth chamber for 2 weeks at $25 \pm 2{ }^{\circ} \mathrm{C}$ with $70 \%$ relative humidity. The acclimatized plants showed normal growth (Fig. 3I), with a $75 \%$ survival rate.

\section{Discussion}

Okra from the Abelmoschus genus is one of the species that show the highest recalcitrance during in vitro regeneration (Anisuzzaman et al., 2010). Till date, successful regeneration of this plant has not been obtained through adventitious shoot production because of phenolic compound production, tissue browning, and explant death (Narendran et al., 2013). However, in recent years, successful attempts to reduce browning and improve regeneration efficiencies of a number of plant species using antibrowning additives in culture media have been reported by various researchers (Kumar et al., 2016; Meziani et al., 2016; Rathore et al., 2015). In our previous study (Irshad et al., 2017), the addition of antibrowning additives significantly altered the PGR concentrations in culture medium and consequently affected the morphogenesis of cultured explants. Therefore, to avoid the negative effects of antibrowning additives in the current study, we added several classes of additives (AC, $\mathrm{AA}$, and $\mathrm{AgNO}_{3}$ ) to PGR free medium, successfully overcoming the browning problem. AC adsorbs the free phenolic compounds secreted by explants into the culture medium (Thomas, 2008) and prevents tissue browning. The previously mentioned porous compound is often used in plant tissue culture, and has been successfully used to alleviate browning in many plant species including Piper chaba (Rani and Dantu, 2016), Lavandula $\times$ intermedia (Erland and Mahmoud, 2014), and Zingiber officinale (Guo et al., 2007). A previous study revealed that the browning of explant tissues during in vitro culture results from enzymatic (PPO) oxidation of phenolic compounds ( $\mathrm{Ru}$ et al., 2013). Ascorbic acid contains ascorbate that has a direct inactivating effect on PPO (Ndakidemi et al., 2014). In addition, AA converts colorless o-quinones resulting from PPO action back to diphenols and prevents browning (Martinez and Whitaker, 1995). According to Titvo et al. (2006), AA scavenges oxygen radicals to prevent the oxidation of phenolic compounds in wounded tissues, thereby reducing tissue browning. In the present study, AA not only alleviated the phenolic secretion from cotyledonary nodes of okra but also improved culture vigor. Similar effects of AA in tissue culture medium were reported by (Ko et al., 2009) during the micropropagation of Cavendish banana and in $V$. faba (Abdelwahd et al., 2008). $\mathrm{AgNO}_{3}$ is a potent ethylene inhibitor, whose use as an antibrowning agent has been previously reported in numerous plant species, including cotton (Gossypium hirsutum) (Kumar et al., 2016) and Solanum chacoense (Castillo et al., 2016). Cotyledonary node explants cultured on medium without antibrowning additives were of poor quality with a few surviving cultures. The addition of $\mathrm{AC}, \mathrm{AA}$, or $\mathrm{AgNO}_{3}$ in $\mathrm{MS}$ basal medium substantially improved the survival of explants, with AA producing the most vigorous cultures, showing that it is a preferable treatment. Although AC significantly reduced the phenolic secretion, some growth inhibition and culture failure were observed in AC treated cultures, which could be related to inhibition of growth by this compound. This phenomenon has been documented for certain plant species including Phoenix dactylifera (Meziani et al., 2016) and Sorghum bicolor (Nguyen et al., 2007). Treatment with $\mathrm{AgNO}_{3}$ showed no significant improvement in culture survival compared with the control treatment. These findings suggest that okra cotyledonary node explant survival and regeneration efficiency can be greatly improved by the supplementation of AA in PGR free MS basal medium.

Plant growth regulators are the key substances for the initiation of plant morphogenic response in vitro. In this study, different concentrations and combinations of BA and NAA were not effective for multiple shoot production compared with TDZ and NAA combinations. TDZ induces a metabolic cascade that results in modification of primary signaling events. For example, it transfers endogenous auxin and acts as a secondary messenger which, in turn, promotes morphogenesis (Biesaga-Kościelniak et al., 2010). The effectiveness of TDZ on shoot regeneration may be explained by the capability of this PGR to stimulate the biosynthesis of endogenous adenine-type cytokinin (Huetteman and Preece, 1993) and/or ability to work as an efficient bioregulator of in vitro morphogenesis (Murthy et al., 1998). Similar to the findings of this study, the formation of many shoots with shorter lengths on medium supplemented with TDZ and auxin has been documented for many plant species including Rhododendron (Ghimire et al., 2016), Exacum travancoricum (Kannan et al., 2007), and Levisticum officinale (Wang et al., 2014). However, the results obtained in this study are not consistent with those obtained by (Ledbetter and Preece, 2004) for in vitro regeneration of Hydrangea quercifolia from leaf explants, which showed that a higher level of TDZ in combination with IBA produced many short shoots, whereas a lower level of TDZ induced fewer and longer shoots. These findings revealed that plant morphogenesis is genotype dependent, which is not only influenced by exogenous PGR action but is also interlinked with PGR synthesis and nutrient uptake (Rubio et al., 2009). Inclusion of regeneration enhancers in culture medium has been reported to be useful for shoot formation and proliferation (Lowe et al., 1994). In the current study, the inclusion of a lower concentration of Pluronic F-68 substantially increased the shoot number and frequency. Recent evidence has indicated that a lower concentration of Pluronic F-68 increases membrane permeability which, in turn, induces morphogenesis, whereas higher concentrations cause detrimental and irreversible changes to the plasma membrane, and thus retard cell growth (Curtis and Mirkov, 2012). The results obtained from this study are in line with the findings observed for Fragaria vesca (Yildirim and Turker, 2014), who achieved efficient shoot proliferation with $0.1 \%$ Pluronic F-68 in combination with moderate levels of TDZ and IBA. Similarly, the regenerationpromoting effect of Pluronic F-68 has been reported for Solanum dulcamara (Kumar 

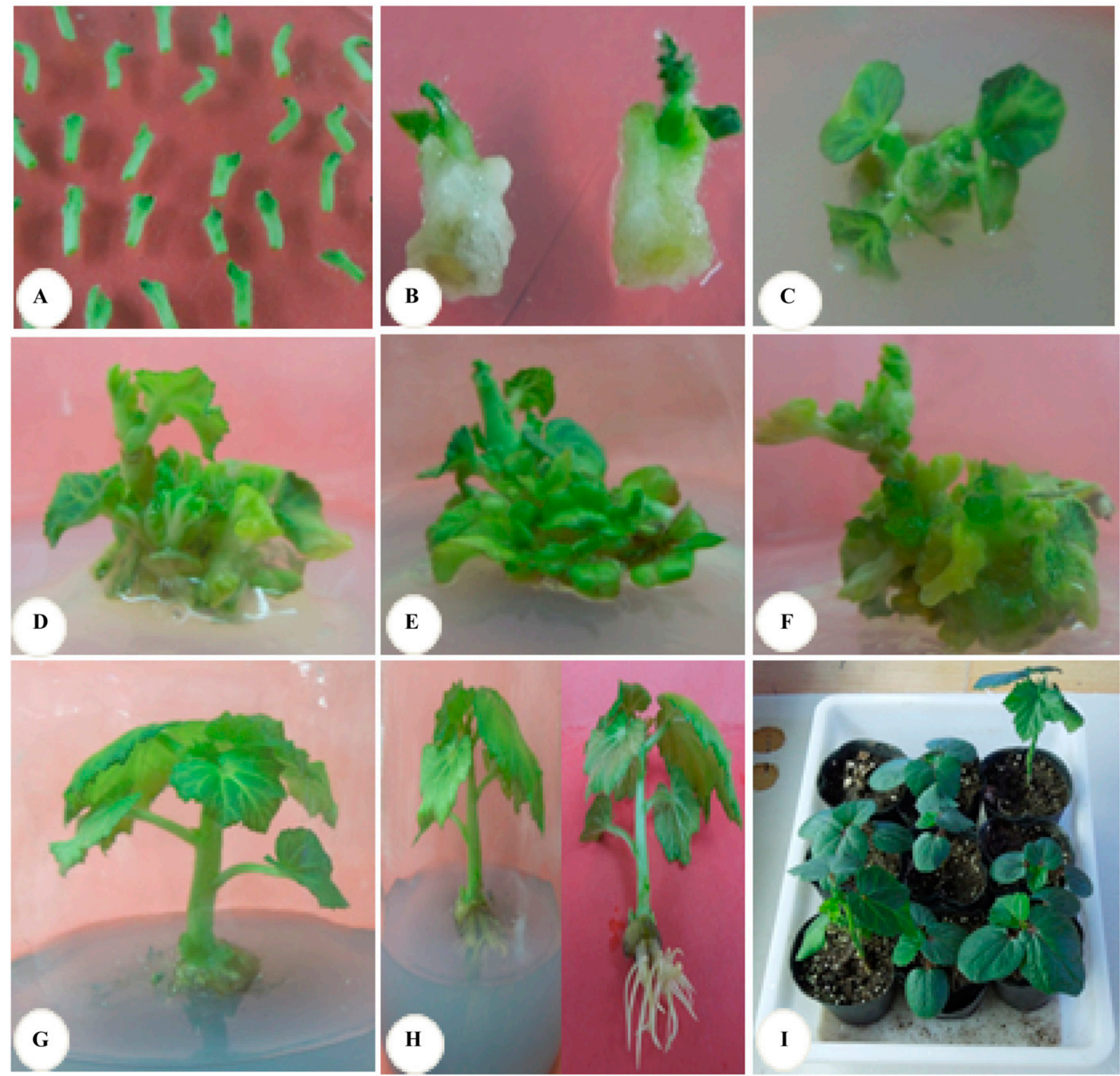

Fig. 3. In vitro regeneration of Abelmoschus esculentus; shoot regeneration through indirect organogenesis from cotyledonary node explants. Cotyledonary node explants (A), vigorous cultures after 2 weeks on AA supplemented medium (B), multiple shoot induction from nodal regions (C), proliferation of multiple shoots on Pluronic F-68 supplemented medium (D and $\mathbf{E}$ ), proliferation of multiple shoots on $\mathrm{AgNO}_{3}$ supplemented medium $(\mathbf{F})$, shoot elongation $(\mathbf{G})$, rooting of elongated shoot $(\mathbf{H})$, and hardening of rooted plants in plastic pots under growth chamber conditions (I).

et al., 1992) and Pyrus communis (Dashti et al., 2012).

Our results obtained with $\mathrm{AgNO}_{3}$ are in contrast to those previously reported where $\mathrm{AgNO}_{3}$ was shown to efficiently promote production and growth of shoots in vitro, such as in cotton (Kumar et al., 2016), peanut (Marka et al., 2015), and knotweed (Kim et al., 2016). The results obtained here suggested that $\mathrm{AgNO}_{3}$ cannot be used as a good additive or a regeneration enhancer for the in vitro regeneration of okra because it is not efficient at reducing phenolic secretion and improving shoot multiplication. However, the actual mechanisms concerning its growth stimulating and inhibiting effects need to be investigated, because the responses vary with plant species.

Shoot elongation is essential for tissue culture, and varies with medium strength and PGR type and concentration in different plant species. $\mathrm{GA}_{3}$ is involved in cell differentiation and elongation, and has been found to be beneficial for the elongation of axial organs including stems and inflorescences (DeMason, 2005). Okra and cotton belong to the Malvaceae family. Recently, Kumar et al. (2016) obtained sufficient shoot elongation during cotton micropropagation with $0.2 \mathrm{mg} \cdot \mathrm{L}^{-1} \mathrm{GA}_{3}$ alone in $\mathrm{MS}$ medium.
However, in our study, the shoot elongation protocol was improved with the combination of BA and $\mathrm{GA}_{3}$. Similar effects of the BA and $\mathrm{GA}_{3}$ combination in tissue culture medium were also noticed in many other plant species, such as in Cucurbita pepo (Ananthakrishnan et al., 2003) and Artemisia vulgaris (Govindaraj and Diana, 2007).

Nutrient deficits act as powerful stimulants for rhizogenesis (Barik et al., 2004). At lower osmotic strength, the root cells take in water effectively and grow into the medium, whereas at higher osmotic strength (i.e., full strength MS medium) initial roots or root cells are not able to take in enough water 
Table 3. Effect of plant growth regulators (PGRs) on elongation of isolated single shoots of Abelmoschus esculentus.

\begin{tabular}{|c|c|c|c|}
\hline \multicolumn{2}{|c|}{ PGRs (mg. $\left.\mathrm{L}^{-1}\right)$} & \multirow[b]{2}{*}{ Shoot length $(\mathrm{cm})$} & \multirow[b]{2}{*}{ Shoot elongation (\%) } \\
\hline$\overline{\mathrm{BA}}$ & $\mathrm{GA}_{3}$ & & \\
\hline$\overline{0}$ & 0 & $1.4 \pm 0.2 \mathrm{e}$ & 14 \\
\hline 0.5 & - & $3.2 \pm 0.2 \mathrm{~cd}$ & 36 \\
\hline 1 & - & $4.6 \pm 0.2 \mathrm{ab}$ & 51 \\
\hline 1.5 & - & $3.5 \pm 0.2 \mathrm{bc}$ & 36 \\
\hline - & 0.1 & $2.0 \pm 0.3 \mathrm{de}$ & 25 \\
\hline - & 0.5 & $3.0 \pm 0.3 \mathrm{scd}$ & 38 \\
\hline - & 1 & $3.3 \pm 0.3 \mathrm{c}$ & 44 \\
\hline 0.5 & 0.5 & $2.8 \pm 0.2 \mathrm{~cd}$ & 47 \\
\hline 1 & 0.1 & $5.3 \pm 0.2 \mathrm{a}$ & 64 \\
\hline 1.5 & 0.1 & $3.4 \pm 0.2 b c$ & 56 \\
\hline
\end{tabular}

Values represent mean $\pm \mathrm{SE}$; data were recorded after 4 weeks of culture. Values with same letter within a column are not significantly different $(P<0.05)$ based on Duncan's multiple range test. Best result is shown in bold. $\mathrm{BA}=$ benzyladenine; $\mathrm{GA}_{3}=$ gibberellic acid.

Table 4. Effect of type and concentration of auxin on root induction of shoots of Abelmoschus esculentus grown on half strength MS with $200 \mathrm{mg} \cdot \mathrm{L}^{-1}$ activated charcoal.

\begin{tabular}{lcccc}
\hline \multicolumn{2}{c}{ Plant growth regulators $\left(\mathrm{mg} \cdot \mathrm{L}^{-1}\right)$} & & & \\
\cline { 1 - 2 } IBA & IAA & Frequency of rooting $(\%)$ & Root no. & Root length $(\mathrm{cm})$ \\
\hline 0 & 0 & 40.0 & $0.7 \pm 0.3 \mathrm{~d}$ & $0.9 \pm 0.1 \mathrm{~d}$ \\
0.1 & - & 65.0 & $2.0 \pm 0.6 \mathrm{bcd}$ & $2.5 \pm 0.3 \mathrm{bcd}$ \\
0.5 & - & 70.0 & $3.3 \pm 0.3 \mathrm{abc}$ & $3.7 \pm 0.1 \mathrm{ab}$ \\
$\mathbf{1}$ & - & $\mathbf{8 2 . 0}$ & $\mathbf{5 . 3} \pm \mathbf{0 . 3} \mathbf{~ a}$ & $\mathbf{4 . 5} \pm \mathbf{0 . 5} \mathbf{~ a}$ \\
1.5 & - & 75.0 & $3.0 \pm 0.6 \mathrm{abcd}$ & $3.4 \pm 0.2 \mathrm{abc}$ \\
2 & - & 70.0 & $2.7 \pm 0.7 \mathrm{bcd}$ & $2.8 \pm 0.4 \mathrm{abc}$ \\
- & 0.1 & 50.0 & $1.3 \pm 0.3 \mathrm{~cd}$ & $1.8 \pm 0.4 \mathrm{~cd}$ \\
- & 0.5 & 55.0 & $2.3 \pm 0.3 \mathrm{bcd}$ & $2.6 \pm 0.3 \mathrm{bcd}$ \\
- & 1 & 60.0 & $3.0 \pm 0.6 \mathrm{abcd}$ & $3.1 \pm 0.5 \mathrm{abc}$ \\
- & 1.5 & 70.0 & $4.0 \pm 0.6 \mathrm{ab}$ & $3.7 \pm 0.2 \mathrm{ab}$ \\
- & 2 & 70.0 & $2.7 \pm 0.3 \mathrm{bcd}$ & $3.0 \pm 0.3 \mathrm{abc}$ \\
\hline
\end{tabular}

Values represent mean \pm SE; data were recorded after 4 weeks of culture. Values with same letter within a column are not significantly different $(P<0.05)$ based on Duncan's multiple range test. Best result is shown in bold. IAA = indole-3-acetic acid; IBA = indole-3-butyric acid.

which causes restricted growth (Satish et al., 2015). On the other hand, AC stimulates nitrogen uptake by shoots and provides dark environment, which promotes in vitro rooting (Thomas, 2008). Therefore, we used half strength MS medium with AC to promote in vitro rooting in $A$. esculentus. Different concentrations of IBA were effective for maximum root regeneration without basal callus formation compared with IAA. Our results are consistent with (Faisal et al., 2014) who reported the best rooting in Mentha arvensis with IBA, whereas IAA was shown to be ineffective because of excessive basal callus formation. Similarly, successful rooting on half strength MS medium containing IBA and AC have been reported in several plant species including Ficus anastasia (Al Malki and Suliman Elmeer, 2009), Jatropha curcas (Rathore et al., 2015), and in Pogostemon cablin Benth (Swamy et al., 2014). Successful acclimatization of plantlets is an essential step in micropropagation. In this study, rooted plantlets acclimatized with vermiculite and sand mixture $(3: 1, \mathrm{v} / \mathrm{v})$ in the greenhouse. The protocol can be used for shoot regeneration, elongation, rooting, and hardening of other cotyledonous species and/ or relevant succulent species.

\section{Conclusion}

An efficient and reproducible protocol for direct shoot regeneration of $A$. esculentus from cotyledonary node explants was developed. Supplementation of AA to basal media minimized the phenolic secretion, improved culture quality, and survival. Furthermore, PGRs, NAA, and TDZ induced shoot multiplication, which was significantly increased with the addition of Pluronic F-68. Moreover, the entire protocol, from seed germination to the establishment of regenerated plants, was accomplished in only three and a half (3.5) months. This optimized in vitro regeneration protocol represents a valuable tool for the genetic transformation of $A$. esculentus.

\section{Literature Cited}

Abdelwahd, R., N. Hakam, M. Labhilili, and S.M. Udupa. 2008. Use of an adsorbent and antioxidants to reduce the effects of leached phenolics in in vitro plantlet regeneration of faba bean. Afr. J. Biotechnol. 7:797-1002.

Al Malki, A. and K. Suliman Elmeer. 2009. Effect of medium strength and charcoal combined with IBA and NAA on root initiation of Ficus anastasia. Acad. J. Plant Sci. 2:169-172.

Ananthakrishnan, G., X. Xia, C. Elman, S. Singer, H. Paris, A. Gal-On, and V. Gaba. 2003. Shoot production in squash (Cucurbita pepo) by in vitro organogenesis. Plant Cell Rpt. 21:739746.

Andersone, U. and G. Ievinsh. 2002. Changes of morphogenic competence in mature Pinus sylvestris L. buds in vitro. Ann. Bot. 90:293-298.

Anisuzzaman, M., A.H. Kabir, K.K. Sarker, S. Jarin, and M.F. Alam. 2010. Micropropagation of Abelmoschus esculentus L. (Moench.) for disease free plantlets through meristem culture. Arch. Phytopath. Plant Prot. 43:460-466.

Bais, H.P., G.S. Sudha, and G.A. Ravishankar. 2000. Putrescine and silver nitrate influences shoot multiplication, in vitro flowering and endogenous titers of polyamines in Cichorium intybus L. cv. Lucknow local. J. Plant Growth Regulat. 19:238-248.

Barik, D., S. Naik, U. Mohapatra, and P. Chand. 2004. High-frequency plant regeneration by in vitro shoot proliferation in cotyledonary node explants of grasspea (Lathyrus sativus L.). In Vitro Cell. Dev. Bio. Plant. 40:467-470.

Biesaga-Kościelniak, J., J. Kościelniak, and A. Janeczko. 2010. The impact of zearalenone and thidiazuron on indirect plant regeneration of oilseed rape and wheat. Acta Physiol. Plant 32:1047-1053.

Castillo, A., P. Gaiero, B.L. Carro, and F. Vilaró. 2016. Gametic embryogenic response in wild diploid solanum species and its implications for genome sequencing projects and breeding. Plant Tissue Cult. Biotechnol. 26:159-173.

Curtis, I.S. and T.E. Mirkov. 2012. Influence of surfactants on growth and regeneration from mature internodal stem segments of sweet orange (Citrussinensis) cv. Hamlin. Plant Cell Tissue Organ Cult. 108:345-352.

Dashti, S., A.A. Habashi, A.V. Azghandi, H Abdollahi, M. Chamani, and S. Dashti. 2012. Effects of pluronic F-68 on regeneration and rooting of two pear cultivars (Pyrus communis cvs Dar Gazi and Bartlett). Intl. Res. J. Appl. Basic Sci. 3:190-196.

DeMason, D.A. 2005. Auxin-cytokinin and auxingibberellin interactions during morphogenesis of the compound leaves of pea (Pisum sativum). Planta 222:151-166.

Düzyaman, E. and H. Vural. 2001. Evaluation of pod characteristics and nutritive value of okra genetic resources. Acta Hort 598:103-110.

Erland, L.A. and S.S. Mahmoud. 2014. An efficient method for regeneration of lavandin (Lavandula xintermedia cv. 'Grosso'). In Vitro Cell. Dev. Bio. Plant. 50:646-654.

Faisal, M., A.A. Alatar, A.K. Hegazy, S.A. Alharbi, M. El-Sheikh, and M.K. Okla. 2014. Thidiazuron induced in vitro multiplication of Mentha arvensis and evaluation of genetic stability by flow cytometry and molecular markers. Ind. Crops Prod. 62:100-106.

FAO. 2013. FAOSTAT database collections. Food and Agriculture Organization of the United Nations, Rome. 27 Mar. 2017. <http://faostat3. fao.org/home >.

Fatokun, C. 1987. Wide hybridization in okra. Theor. Appl. Genet. 74:483-486.

Fernandez, S., N. Michaux-Ferrière, and M Coumans. 1999. The embryogenic response of immature embryo cultures of durum wheat (Triticum durum Desf.): Histology and improvement by $\mathrm{AgNO}_{3}$. Plant Growth Regulat. 28:147-155.

Gerszberg, A., K. Hnatuszko-Konka, and T. Kowalczyk. 2015. In vitro regeneration of eight cultivars of Brassica oleracea var. capitata. In Vitro Cell. Dev. Bio. Plant. 51:80-87.

Ghimire, B.K., E.S. Seong, T.X. Nguyen, C.Y. Yu, S.H. Kim, and I-M. Chung. 2016. In vitro regeneration of Melastoma malabatricum Linn. through organogenesis and assessment of clonal and biochemical fidelity using RAPD and HPLC. Plant Cell Tissue Organ Cult. 124:517-529.

Govindaraj, S. and R.K.B. Diana. 2007. Efficient in vitro micropropagation and regeneration of Artemisia vulgaris L. Crop Breed. Appl. Biotechnol. 7:117-124. 
Guo, Y., J. Bai, and Z. Zhang. 2007. Plant regeneration from embryogenic suspensionderived protoplasts of ginger (Zingiber officinale Rosc.). Plant Cell Tissue Organ Cult. 89:151-157.

Hamon, S. and D. Van Sloten. 1995. Okra: Abelmoschus esculentus, A. caillei, A. manihot, A. moschatus (Malvaceae), p. 350-357. In: J. Smartt and N.W. Simmonds (eds.). Evolution in crop plants. Longman, Harlow, UK.

Haque, M., A.B. Siddique, and S.S. Islam. 2015. Effect of silver nitrate and amino acids on high frequency plants regeneration in barley (Hordeum vulgare L.). Plant Tissue Cult. Biotech. 25:37-50.

Hedayat, M., G. Abdi, and M. Khosh-Khui. 2009. Regeneration via direct organogenesis from leaf and petiole segments of pyrethrum [Tanacetum cinerariifolium (Trevir.) Schultz-Bip.]. Amer. Eurasian J. Agr. Environ. Sci. 6:81-87.

Horemans, N., C.H. Foyer, and H. Asard. 2000 Transport and action of ascorbate at the plant plasma membrane. Trends Plant Sci. 5:263267.

Huetteman, C.A. and J.E. Preece. 1993. Thidiazuron: A potent cytokinin for woody plant tissue culture. Plant Cell Tissue Organ Cult. 33:105-119.

Irshad, M., S. Liu, B.Z. He, B. Debnath, M. Li, H.M. Rizwan, and D.L. Qiu. 2017. In vitro regeneration of Abelmoschus esculentus L. cv. Wufu: Influence of anti-browning additives on phenolic secretion and callus formation frequency from explant. Hort. Environ. Biotechnol. 58:503-513.

Jain, P., S. Kachhwaha, and S. Kothari. 2014. Chloroplast ultra structure, photosynthesis and enzyme activities in regenerated plants of Stevia rebaudiana (Bert.) Bertoni as influenced by copper sulphate in the medium. Indian $\mathrm{J}$. Expt. Biol. 52:898-904.

Jones, A.M.P. and P.K. Saxena. 2013. Inhibition of phenylpropanoid biosynthesis in Artemisia annua L.: A novel approach to reduce oxidative browning in plant tissue culture. PLoS One 8: e76802.

Kabir, A., K. Sarker, S. Sharmin, M. Islam, and M. Alam. 2008. Callus induction and plantlet regeneration in Abelmoschus esculentus (L.). Moench. J. Agr. Tech. 4:193-204.

Kabir, K.M.R., S.W. Kwon, and Y.J. Park. 2013. Application of cobalt chloride and silver nitrate for efficient microspore culture of Brassica rapa ssp. Plant Tissue Cult. Biotechnol. 23:1-10.

Kannan, P., A. Premkumar, and S. Ignacimuthu. 2007. Thidiazuron induced shoot regeneration in the endangered species, Exacum travancoricum Beedi. Intl. J. Biotechnol. 6:564-566.

Kaviani, B. 2014. Effect of ascorbic acid concentration on structural characteristics of appical meristems on in vitro Aloe barbadensis Mill. Acta Sci. Pol. Technol. Aliment. 13:49-56.

Kim, J.K., T.B. Baskar, and S.U. Park. 2016. Silver nitrate and putrescine enhance in vitro shoot organogenesis in Polygonum tinctorium. Biosci. Biotechnol. Res. Asia 13:53-58.

Klenotičová, H., I. Smýkalová, L. Švábová, and M. Griga. 2013. Resolving browning during the establishment of explant cultures in Vicia faba L. for genetic transformation. Acta Univ. Agr. Silvic. Mendel. Brun. 61:1279-1288.

Ko, W., C. Su, C. Chen, and C. Chao. 2009. Control of lethal browning of tissue culture plantlets of Cavendish banana cv. Formosana with ascorbic acid. Plant Cell Tissue Organ Cult. 96:137-141.
Kumar, G.P., S. Sivakumar, G. Siva, M. Vigneswaran, T.S. Kumar, and N. Jayabalan. 2016. Silver nitrate promotes high-frequency multiple shoot regeneration in cotton (Gossypium hirsutum L.) by inhibiting ethylene production and phenolic secretion. In Vitro Cell. Dev. Biol. Plant 52:408-418.

Kumar, G.P., S. Subiramani, S. Govindarajan, V. Sadasivam, V. Manickam, K. Mogilicherla, S.K. Thiruppathi, and J. Narayanasamy. 2015. Evaluation of different carbon sources for high frequency callus culture with reduced phenolic secretion in cotton (Gossypium hirsutum L.) cv. SVPR-2. Biotechnol Rpt. 7:72-80.

Kumar, V., L. Laouar, M. Davey, B. Mulligan, and K. Lowe. 1992. Pluronic F-68 stimulates growth of Solanum dulcamara in culture. J. Expt. Bot. 43:487-493.

Kumar, V., G. Parvatam, and G.A. Ravishankar. 2009. $\mathrm{AgNO}_{3}$ : A potential regulator of ethylene activity and plant growth modulator. Electron. J. Biotechnol. 12:8-9.

Ledbetter, D.I. and J.E. Preece. 2004. Thidiazuron stimulates adventitious shoot production from Hydrangea quercifolia Bartr. leaf explants. Scientia Hort. 101:121-126.

Lorenzo, J.C., M. de los Angeles Blanco, O. Peláez, A. González, M. Cid, A. Iglesias, B. González, M. Escalona, P. Espinosa, and C. Borroto. 2001. Sugarcane micropropagation and phenolic excretion. Plant Cell Tissue Organ Cult. 65:1-8.

Lowe, K., M. Davey, L. Laouar, A. Khatun, R. Ribeiro, J. Power, and B. Mulligan. 1994. Surfactant stimulation of growth in cultured plant cells, tissues and organs, p. 234-244. In: P.J. Lumsden, J.R. Nicholas, and W.J. Davies (eds.). Physiology, growth and development of plants in culture. Springer, Dordrecht.

Mangat, B. and M. Roy. 1986. Tissue culture and plant regeneration of okra (Abelmoshus esculentus). Plant Sci. 47:57-61.

Marka, R., M. Banala, and N.R. Swamy. 2015 Influence of silver nitrate on leaflet based direct degeneration in Arachis hypogaea L. VegetosAn. Intl. J. Plant Res. 28:63-69.

Martinez, M.V. and J.R. Whitaker. 1995. The biochemistry and control of enzymatic browning. Trends Food Sci. Technol. 6:195-200.

Meziani, R., F. Jaiti, M.A. Mazri, A. Hassani, S.B. Salem, M. Anjarne, M.A. Chitt, and C. Alem. 2016. Organogenesis of Phoenix dactylifera L. cv. Mejhoul: Influences of natural and synthetic compounds on tissue browning, and analysis of protein concentrations and peroxidase activity in explants. Scientia Hort. 204:145-152.

Mookkan, M. and G. Andy. 2014. $\mathrm{AgNO}_{3}$ boosted high-frequency shoot regeneration in Vigna mungo (L.) Hepper. Plant Signal. Behav. 9: e972284.

Murthy, B., S. Murch, and P.K. Saxena. 1998. Thidiazuron: A potent regulator of in vitro plant morphogenesis. In Vitro Cell. Dev. Biol. Plant 34:267.

Narendran, M., S.G. Deole, S. Harkude, D. Shirale, A. Nanote, P. Bihani, S. Parimi, B.R. Char, and U.B. Zehr. 2013. Efficient genetic transformation of okra (Abelmoschus esculentus (L.) Moench) and generation of insect-resistant transgenic plants expressing the cry1Ac gene. Plant Cell Rpt. 32:1191-1198.

Ndakidemi, C.F., E. Mneney, and P.A. Ndakidemi. 2014. Effects of ascorbic acid in controlling lethal browning in in vitro culture of Brahylaena huillensis using nodal segments. Amer. J. Plant Sci. 5:187-191.
Nguyen, T-V., T.T. Thu, M. Claeys, and G. Angenon. 2007. Agrobacterium-mediated transformation of sorghum (Sorghum bicolor (L.) Moench) using an improved in vitro regeneration system. Plant Cell Tissue Organ Cult. 91:155-164.

Nwangburuka, C., O. Kehinde, O. Adegbite, and O. Denton. 2011. Mitotic chromosomes in Abelmoschus esculentus (L.) Moench esculentus (L.). Moench. Ann. Bio. Res. 2:85-90.

Rani, D. and P.K. Dantu. 2016. Sustained shoot multiplication and method for overcoming in vitro browning in medicinally important plant, Piper chaba hunt. Proc. Natl. Acad. Sci. Ind. Biol. Sci. 86:407-413.

Rathore, M.S., S. Yadav, P. Yadav, J. Kheni, and B. Jha. 2015. Micropropagation of elite genotype of Jatropha curcas L. through enhanced axillary bud proliferation and ex vitro rooting. Biom. Bioen. 83:501-510.

Ru, Z., Y. Lai, C. Xu, and L. Li. 2013. Polyphenol oxidase (PPO) in early stage of browning of Phalaenopsis leaf explants. J. Agr. Sci. 5:57-63.

Rubio, V., R. Bustos, M.L. Irigoyen, X. CardonaLópez, M. Rojas-Triana, and J. Paz-Ares. 2009. Plant hormones and nutrient signaling. Plant Mol. Biol. 69:361-371.

Sabitha, V., S. Ramachandran, K. Naveen, and K. Panneerselvam. 2011. Antidiabetic and antihyperlipidemic potential of Abelmoschus esculentus (L.) Moench. in streptozotocin-induced diabetic rats. J. Pharm. Bioallied Sci. 3:397.

Satish, L., R. Rameshkumar, P. Rathinapriya, S. Pandian, A.S. Rency, T. Sunitha, and M. Ramesh. 2015. Effect of seaweed liquid extracts and plant growth regulators on in vitro mass propagation of brinjal (Solanum melongena L.) through hypocotyl and leaf disc explants. J. App. Phych. 27:993-1002.

Sunilson, J., P. Jayaraj, M. Mohan, A. Kumari, and R. Varatharajan. 2008. Antioxidant and hepatoprotective effect of the roots of Hibiscus esculentus Linn. Intl. J. Green Pharm. 2:200.

Swamy, M.K., S.K. Mohanty, and M. Anuradha. 2014. The effect of plant growth regulators and natural supplements on in vitro propagation of Pogostemon cablin Benth. J. Crop Sci. Biotechnol. 17:71-78.

Tabiyeh, D., F. Bernard, and H. Shacker. 2005. Investigation of glutathione, salicylic acid and $\mathrm{GA}_{3}$ effects on browning in Pistacia vera shoot tips culture. Acta Hort 726:201-204.

Thomas, T.D. 2008. The role of activated charcoal in plant tissue culture. Biotechnol. Adv. 26:618-631.

Titov, S., S.K. Bhowmik, A. Mandal, M.S. Alam, and S.N. Uddin. 2006. Control of phenolic compound secretion and effect of growth regulators for organ formation from Musa spp. cv. Kanthali floral bud explants. Amer. J. Biochem. Biotechnol. 2:97-104.

Yildirim, A.B. and A.U. Turker. 2014. Effects of regeneration enhancers on micropropagation of Fragaria vesca L. and phenolic content comparison of field-grown and in vitro-grown plant materials by liquid chromatographyelectrospray tandem mass spectrometry (LCESI-MS/MS). Scientia Hort. 169:169-178.

Wang, Q., Y. Ran, B. Yu, X. Chen, and D. Wang. 2014. Embryogenesis and haploid induction using anther culture in lovage (Levisticum officinale WDJ Koch). In Vitro Cell. Dev. Biol. Plant 50:525-533. 